\section{Blue Light Monochromatic Irradiation for 12 Hours in Lighting Pattern with Combinations of Blue and Red Light Elongates Young Cos Lettuce Leaves and Promotes Growth under High Daily Light Integral}

Tomohiro Jishi

Department of Biological and Environmental Engineering, Graduate School of Agricultural and Life Sciences, the University of Tokyo 1-1-1 Yayoi, Bunkyo, Tokyo, 113-8657, Japan; and Energy Innovation Center, Central Research Institute of Electric Power Industry 1646 Abiko, Abikoshi, Chiba, 270-1194, Japan

Ryo Matsuda and Kazuhiro Fujiwara

Department of Biological and Environmental Engineering, Graduate School of Agricultural and Life Sciences, the University of Tokyo 1-1-1 Yayoi, Bunkyo, Tokyo, 113-8657, Japan

Additional index words. artificial lighting, blue-light receptor, leaf elongation, LED, photomorphogenesis, phytochrome

Abstract. Cos lettuce was grown under different spectral photon flux density distribution (SPFD) change patterns with blue- and/or red light-emitting diode (LED) irradiation with a 24-hour cycle. Twelve treatments were designed with a combination of four relative SPFD (RSPFD) change patterns and three photosynthetic photon flux density (PPFD) levels. The RSPFD change patterns were as follows: BR/BR, simultaneous blue- and red-light irradiation (BR) for $24 \mathrm{~h}$; $R / B R$, red-light monochromatic irradiation ( $R$ ) for $12 \mathrm{~h}$ followed by 12 hours of $B R$; $B / B R$, blue-light monochromatic irradiation (B) for 12 hours followed by 12 hours of $B R$; and $B / R, 12$ hours of $B$ followed by 12 hours of $R$. Each RSPFD change pattern was conducted at three daily average photosynthetic photon flux densities $\left(\right.$ PPFD $\left._{\text {ave }}\right)$ of 50,100 , and 200 $\mu \mathrm{mol} \cdot \mathrm{m}^{-2} \cdot \mathrm{s}^{-1}$. The RSPFD change patterns that included $B(B / B R$ and $B / R)$ resulted in elongated leaves. A low ratio of active phytochrome to total phytochrome under $B$ was considered the reason for leaf elongation. Shoot dry weight was significantly greater under the RSPFD change patterns that included $B$ when the PPFD ave $_{\text {wa }} 200$ $\mu \mathrm{mol} \cdot \mathrm{m}^{-2} \cdot \mathrm{s}^{-1}$. The leaf elongation caused by $B$ would have increased the amount of light received and thereby promoted growth. However, excessive leaf elongation caused the plants to fall, and growth was not promoted under the RSPFD change patterns that included B when the $\mathrm{PPFD}_{\text {ave }}$ was $50 \mu \mathrm{mol} \cdot \mathrm{m}^{-2} \cdot \mathrm{s}^{-1}$. Thus, 12-hour B promoted growth under conditions in which leaf elongation leads to increases in the amount of light received.

Many researchers have attempted to use the knowledge acquired through previous studies on the effects of light to improve plant cultivation under artificial lighting. Some studies have suggested that a combination of blue and red light is suitable for plant cultivation (Liu et al., 2012; Yorio et al., 2001).

Received for publication 29 Apr. 2021. Accepted for publication 28 May 2021.

Published online 9 July 2021

This work was supported by JSPS KAKENHI Grant Number JP20K15633.

T.J. is the corresponding author. E-mail: jishi@ criepi.denken.or.jp.

This is an open access article distributed under the CC BY-NC-ND license (https://creativecommons. org/licenses/by-nc-nd/4.0/). irradiation of blue and red light. The authors also suggested that leaf expansion caused by blue- and/or red-light monochromatic irradiation possibly contributed to the promotion of plant growth. Chen et al. (2017) grew leaf lettuce with a 16-h light/8-h dark cycle and observed that under alternating blue and red light irradiation the leaves were thinly expanded compared with those under simultaneous blue and red light irradiation. However, shoot fresh weight and dry weight were greater under simultaneous blue- and redlight irradiation. It remains unclear whether blue- and/or red-light monochromatic irradiation promotes growth through a change in morphology. With an improved understanding of plant growth and morphological responses, lighting methods are expected to be developed to promote plant growth with increased efficiency.

In this study, we observed the effects of SPFD change patterns in combination with blue and red LED light on the growth and morphology of cos lettuce. The four RSPFD change patterns were designed to investigate the effects of 12-h blue light monochromatic irradiation (B) and red-light monochromatic irradiation (R).

Although a time course of RSPFD can affect growth through morphological changes, PPFD is also known to affect morphology (e.g., Fan et al., 2013; Kitaya et al., 1998). The effects of RSPFD change pattern on morphology and growth might show interactions with the effects of PPFD. Therefore, we investigated the effects of the four RSPFD change patterns on morphology and growth of cos lettuce at three daily average PPFD $\left(\mathrm{PPFD}_{\mathrm{ave}}\right)$ levels to identify possible interactions between the effects of RSPFD change patterns and PPFD $_{\text {ave }}$.

\section{Materials and Methods}

Plant material. Seeds of cos lettuce (Lactuca sativa L. 'Cos Lettuce'; Takii Seed Co., Ltd., Kyoto, Japan), which referred to as romaine lettuce in some areas, were sown on watered urethane-foam cubes and placed in a temperature-controlled chamber (MIR-553; SANYO Electric Co., Ltd., Osaka, Japan) at $25 \pm 1{ }^{\circ} \mathrm{C}$ under a $16 \mathrm{~h}$-light $/ 8 \mathrm{~h}$-dark cycle. Light was provided with white LEDs at a PPFD of $\approx 100 \mu \mathrm{mol} \cdot \mathrm{m}^{-2} \cdot \mathrm{s}^{-1}$. The PPFD values were measured with a photon sensor (LI-190SA; LI-COR, Lincoln, NE) and a dedicated display (LI-1400; LI-COR). Seven days after sowing, seedlings with ca. 1-cmlong first true leaves were selected and used for cultivation experiments.

Irradiation pattern treatments. The PPFD values stated below were measured at a height of $2.5 \mathrm{~cm}$ from the cultivation surface, which is equivalent to the height of the leaf surface at the start of the cultivation experiment. Because the LED panel was sufficiently large, the PPFD value at each seedling position was within \pm 5 $\mu \mathrm{mol} \cdot \mathrm{m}^{-2} \cdot \mathrm{s}^{-1}$ of the set value. The distance between the LED panel and the cultivation surface was fixed to $\approx 30 \mathrm{~cm}$ during cultivation, hence the upper portion of plants tended to 

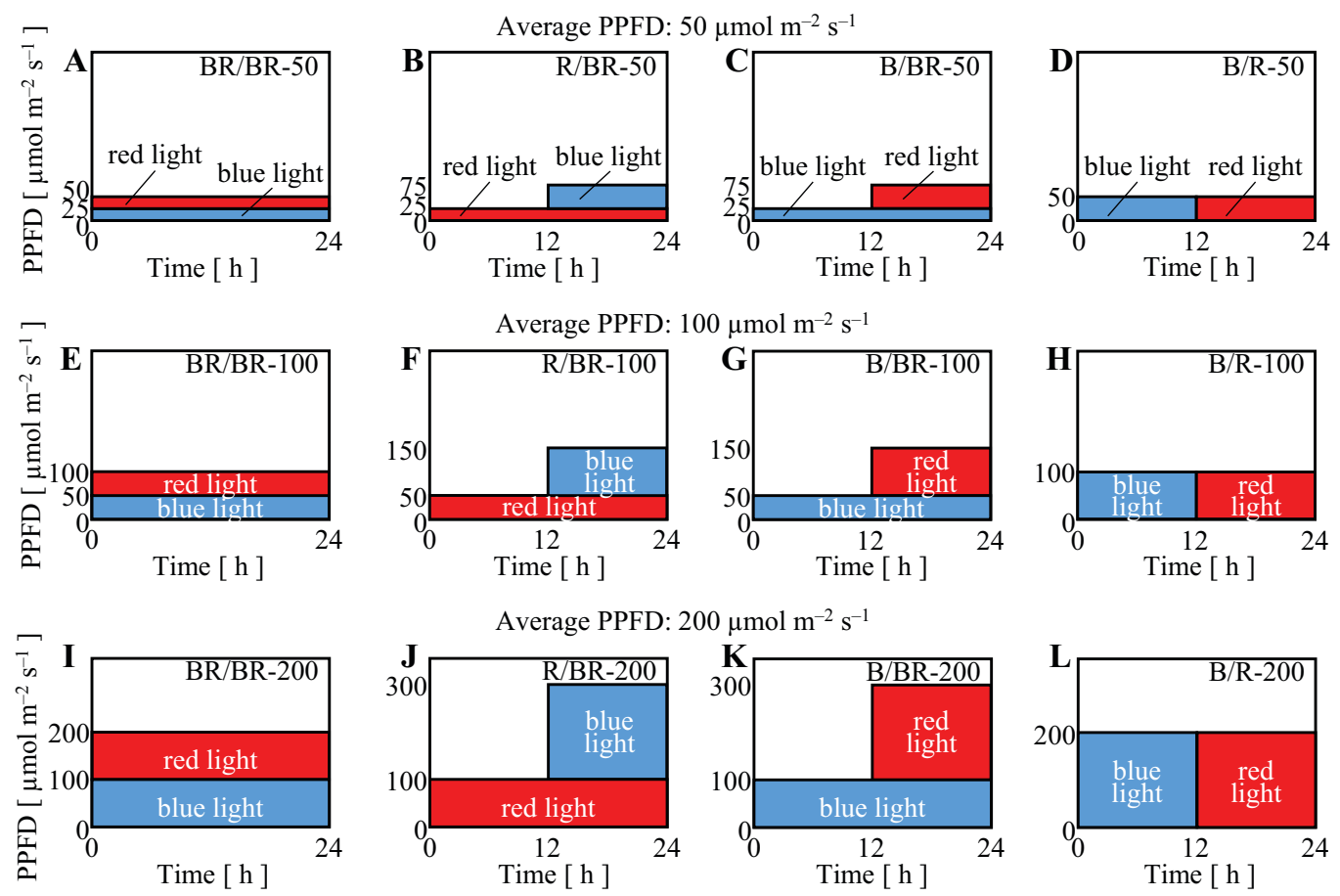

Fig. 1. Light irradiation treatments consisting of four relative spectral photosynthetic photon flux density change patterns-(A, E, I) BR/BR; (B, F, J) R/BR; $(\mathbf{C}, \mathbf{G}, \mathbf{K}) \mathrm{B} / \mathrm{BR} ;(\mathbf{D}, \mathbf{H}, \mathbf{L}) \mathrm{B} / \mathrm{R}$ - over a 24-h cycle in combination with three daily average photon flux density densities (PPFDs) of (A-D) 50, (E-H) 100 , or $(\mathbf{I}-\mathbf{L}) 200 \mu \mathrm{mol} \cdot \mathrm{m}^{-2} \cdot \mathrm{s}^{-1}$. B = blue-light monochromatic irradiation; BR = blue- and red-light irradiation; $\mathrm{R}=$ red-light monochromatic irradiation.

receive light with a higher PPFD. Twelve treatments were applied as combinations of the four RSPFD change patterns and three PPFD levels. The RSPFD change patterns were as follows; BR/BR: simultaneous blue and red light irradiation (BR) for $24 \mathrm{~h}$; R/BR: red light monochromatic irradiation $(\mathrm{R})$ for $12 \mathrm{~h}$ followed by $\mathrm{BR}$ for $12 \mathrm{~h}$; B/BR: blue-light monochromatic irradiation (B) for $12 \mathrm{~h}$ followed by BR for $12 \mathrm{~h}$; and $\mathrm{B} / \mathrm{R}$ : $\mathrm{B}$ for $12 \mathrm{~h}$ followed by $\mathrm{R}$ for $12 \mathrm{~h}$. These four RSPFD change patterns were conducted at three daily $\mathrm{PPFD}_{\text {ave }}$ values of 50, 100, and $200 \mu \mathrm{mol} \cdot \mathrm{m}^{-2} \cdot \mathrm{s}^{-1}$ (Fig. 1). The treatments are referred to as the combination of RSPFD change pattern and $\mathrm{PPFD}_{\text {ave }}$, such as BR/BR50. The four RSPFD change patterns were designed with combination of the presence or absence of 12-h B and R (Table 1), and the blue and red daily light integral (DLI) in treatments of the same PPFD ave were equalized to reduce effects other than those of $B$ and $R$. To equalize the DLIs of both blue and red light among treatments, the PPFDs of 12-h blue- and red-light irradiation were set as double the PPFDs of 24$\mathrm{h}$ blue- and red-light irradiation, respectively, for each PPFD $_{\text {ave }}$ (Fig. 1). The DLI was 4.3, 8.6 , and $17.3 \mathrm{~mol} \cdot \mathrm{m}^{-2}$ in treatments with $\mathrm{PPFD}_{\text {ave }}$ of 50,100 , and $200 \mu \mathrm{mol} \cdot \mathrm{m}^{-2} \cdot \mathrm{s}^{-1}$, respectively (Table 1 ).

Cultivation experiments. A total of 16 uniformly sized cos lettuce seedlings grown under white LED light were transplanted individually together with the urethane-foam cubes to holes in white acrylic boards. Four seedlings were transplanted to each of four individual boards. Each board was put on a 5-L plastic container filled with continuously aerated nutrient solution (half-strength Otsuka-A nutrient solution;
OAT Agrio Co. Ltd., Tokyo, Japan) with EC of $0.13 \pm 0.01 \mathrm{~S} \cdot \mathrm{m}^{-1}$. The internal spaces of two temperature-controlled chambers were partitioned into upper and lower compartments with cardboard and black paper to prevent light contamination from either compartment. Four seedlings were cultivated in each of the four compartments under different SPFD change patterns. The air temperature was maintained at $25 \pm 1{ }^{\circ} \mathrm{C}$ throughout the day for all compartments. The $\mathrm{CO}_{2}$ concentration and relative humidity were not measured or controlled but were expected to have been similar in all treatment groups because external air was continuously introduced into each compartment. Fourteen days after the start of cultivation (21 $\mathrm{d}$ after sowing), the plants were harvested to record the shoot dry weight, leaf area, and leaf length. The shoots were dried for $1 \mathrm{~h}$ at $100^{\circ} \mathrm{C}$ and then dried at $80^{\circ} \mathrm{C}$ for $3 \mathrm{~d}$ before measurement of the shoot dry weight. The leaf area of leaves longer than $3 \mathrm{~cm}$ was measured using an area meter (AAM-9; Hayashi Denko Co. Ltd., Tokyo, Japan). The length of the largest leaf on each plant was measured with a ruler. The cultivation experiments were repeated twice for each of the 12 treatments, and the compartments were randomly selected for each replication.

Light sources. White LED (NSPW310DSb2W; Nichia Corp., Tokushima, Japan) arrays were used for seedling growth before the cultivation experiments. Peaks for the white LED light occurred at $459 \mathrm{~nm}$ (sharp peak from the LED-chip emission) and $583 \mathrm{~nm}$ (broad peak from phosphor wavelength conversion). Blue (HBL3-3S55-LE; Toricon, Shimane, Japan) and red (SRK1-3A80-LE; Toricon) LED

Table 1. Relative spectral photon flux density (RSPFD) change pattern, average photosynthetic photon flux density (PPFD), daily light integral (DLI), presence or absence of blue- and red-light monochromatic irradiation ( $\mathrm{B}$ and $\mathrm{R}$, respectively), durations of blue light and red light irradiation, and average phytochrome photostationary state (PSS) of each treatment. The units for average PPFD and DLI are $\mu \mathrm{mol} \cdot \mathrm{m}^{-2} \cdot \mathrm{s}^{-1}$ and $\mathrm{mol} \cdot \mathrm{m}^{-2} \mathrm{~d}^{-1}$, respectively.

\begin{tabular}{lccccccc}
\hline Treatment & $\begin{array}{c}\text { RSPFD } \\
\text { change pattern }\end{array}$ & $\begin{array}{c}\text { Avg } \\
\text { PPFD/DLI }\end{array}$ & B presence & R presence & B & R & Avg PSS \\
\hline BR/BR-50 & BR/BR & $50 / 4.3$ & Absent & Absent & $24 \mathrm{~h}$ & $24 \mathrm{~h}$ & 0.89 \\
BR/BR-100 & & $100 / 8.6$ & & & & & \\
BR/BR-200 & & $200 / 17.3$ & & & & & \\
R/BR-50 & R/BR & $50 / 4.3$ & Absent & Present & $12 \mathrm{~h}$ & $24 \mathrm{~h}$ & 0.90 \\
R/BR-100 & & $100 / 8.6$ & & & & & \\
R/BR-200 & & $200 / 17.3$ & & & \multirow{2}{*}{$24 \mathrm{~h}$} & $12 \mathrm{~h}$ & 0.67 \\
B/BR-50 & B/BR & $50 / 4.3$ & Present & Absent & & & \\
B/BR-100 & & $100 / 8.6$ & & & & & \\
B/BR-200 & B/R & $200 / 17.3$ & & & & & \\
B/R-50 & & $50 / 4.3$ & Present & Present & $12 \mathrm{~h}$ & $12 \mathrm{~h}$ & 0.68 \\
B/R-100 & & $100 / 8.6$ & & & & & \\
B/R-200 & & $200 / 17.3$ & & & & & \\
\hline
\end{tabular}



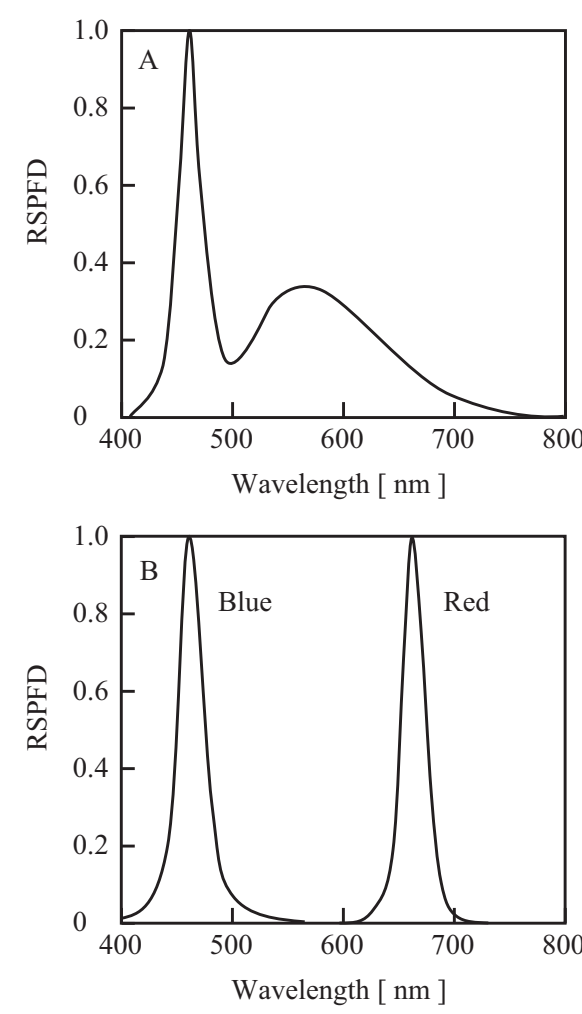

Fig. 2. Relative spectral photon flux density (SPFD) distribution of light provided by (A) white light-emitting diode (LEDs) used for seedling cultivation and (B) blue and red LEDs used for the cultivation experiment. arrays were used for the cultivation experiments. The RSPFDs of the white, blue, and red LED lights are shown in Fig. 2. Peaks for blue and red LED light occurred at 463 and $656 \mathrm{~nm}$, respectively. The LED arrays were connected to DC power supplies (blue: PAS60-4.5; red and white: PMC35-1A; Kikusui Electronics Corp., Yokohama, Japan). The PPFD was adjusted to the desired value by regulating the electric current supplied by the DC power supply. Digital timers (H5CX, OMRON Corp., Kyoto, Japan) were connected to the DC power supplies and used to remotely control the irradiation cycles.

Statistical analysis. Mean separations for each PPFD $_{\text {ave }}$ level were analyzed using the Tukey-Kramer honest significant difference test $(P=0.05)$. In addition, we performed a three-way analysis of variance (ANOVA) using $B$ presence, $R$ presence, and $P_{P F D}$ ave as the main factors. The statistical analysis was performed using R software (https://cran. r-project.org/).

\section{Results}

At all PPFD ${ }_{\text {ave }}$ levels under the treatments that included $B$ (RSPFD change patterns of $\mathrm{B} / \mathrm{BR}$ and $\mathrm{B} / \mathrm{R}$ ), the leaves appeared elongated and thin (Fig. 3). At PPFD $_{\text {ave }}$ of 50 $\mu \mathrm{mol} \cdot \mathrm{m}^{-2} \cdot \mathrm{s}^{-1}$, the plants were excessively elongated and fell over under B/BR-50 and B/R-50 (Fig. 3C and D). There were no significant differences in shoot dry weight, leaf area, or leaf length among the treatments for plants grown at $50 \mu \mathrm{mol} \cdot \mathrm{m}^{-2} \cdot \mathrm{s}^{-1}$ (Fig. $4 \mathrm{~A}-\mathrm{C}$ ), although the plant appearance was obviously different (Fig. 3A-D). At PPFD ave of $100 \mu \mathrm{mol} \cdot \mathrm{m}^{-2} \cdot \mathrm{s}^{-1}$, compared with BR/BR-100 and R/BR-100 (Fig. 3E and F), $\mathrm{B} / \mathrm{BR}-100$ and $\mathrm{B} / \mathrm{R}-100$ that included $\mathrm{B}$ resulted in leaf expansion in a flat manner without curling at the margins (Fig. 3G and $\mathrm{H})$. There were no significant differences in shoot dry weight, whereas average shoot dry weight (Fig. 4D), leaf area (Fig. 4E), and leaf length (Fig. 4F) with B/BR-100 and B/R-100 were more than $20 \%$ higher than those with $\mathrm{BR} / \mathrm{BR}-100$ and $\mathrm{R} / \mathrm{BR}-100$. At $\mathrm{PPFD}_{\text {ave }}$ of $200 \mu \mathrm{mol} \cdot \mathrm{m}^{-2} \cdot \mathrm{s}^{-1}$, compared with BR/BR200 and R/BR-200 (Fig. 3I and J), B/BR-200 and $\mathrm{B} / \mathrm{R}-200$ that included $\mathrm{B}$ resulted in leaf expansion in a flat manner (Fig. $3 \mathrm{~K}$ and L). Shoot dry weight, leaf area, and leaf length in B/BR-200 and B/R-200 were significantly greater than those in BR/BR-200 and R/BR200 , and the differences in the values were more than $50 \%$ (Fig. 4G-I).

The three-way ANOVA results showed that $\mathrm{B}$ presence and $\mathrm{PPFD}_{\text {ave }}$ significantly affected shoot dry weight and leaf area (Table $2)$. There were interactions between B presence and PPFD $_{\text {ave }}$ for shoot dry weight, leaf area, and leaf length (Table 2). Irradiation with R significantly affected leaf area and leaf length. Comparison of the RSPFD change patterns of $B / B R$ and $B / R$ (which included $B$ ) showed that leaf area and leaf length tended to be smaller under $B / R$, which included R. Similarly, comparison of R/BR
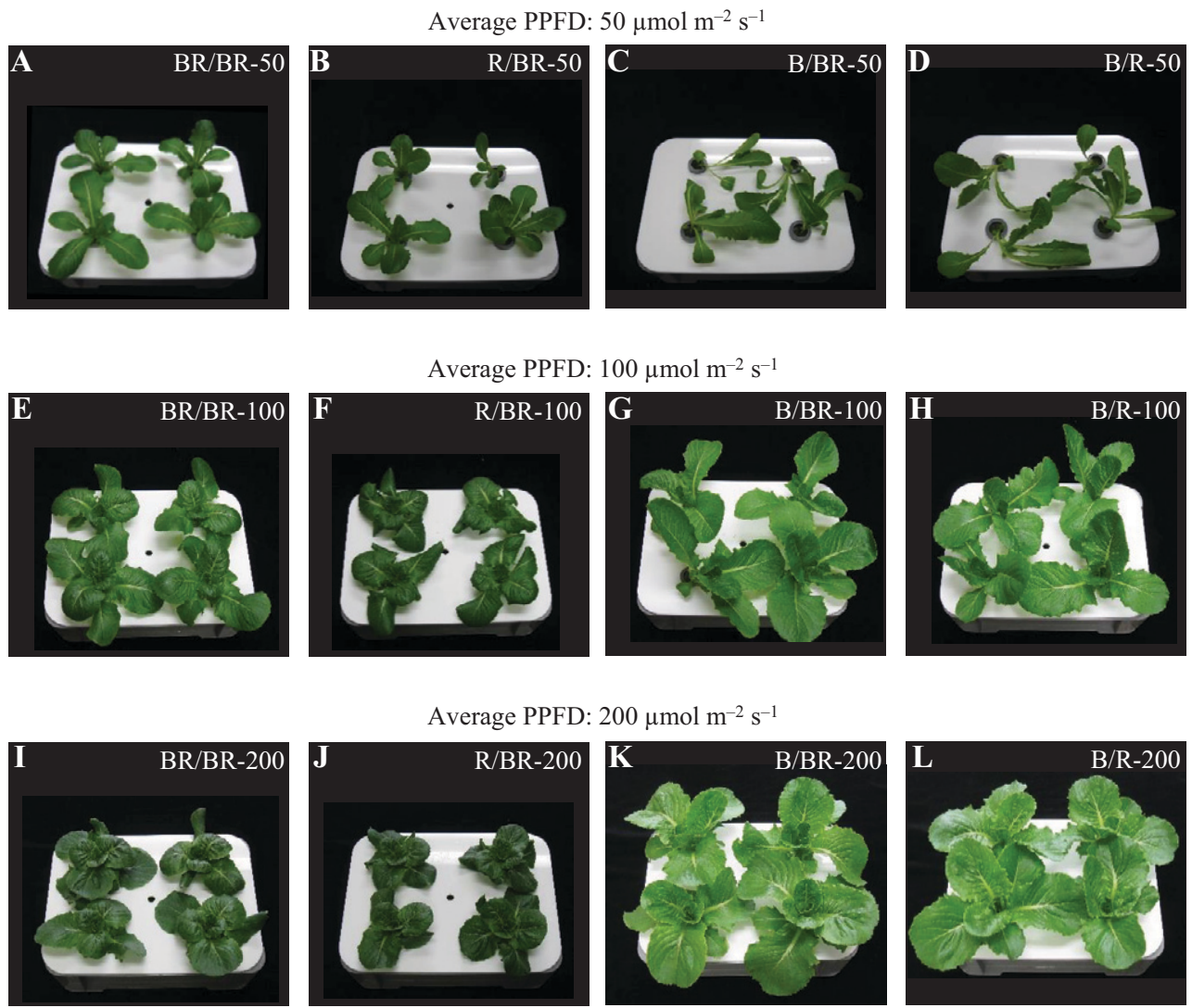

Fig. 3. Cos lettuce plants grown under each irradiation treatment (see Fig. 1) with a daily average photosynthetic photon flux density (PPFD) of (A-D) 50, (E-H) 100 , or $(\mathbf{I}-\mathbf{L}) 200 \mu \mathrm{mol} \cdot \mathrm{m}^{-2} \cdot \mathrm{s}^{-1}$ for $14 \mathrm{~d}$. 

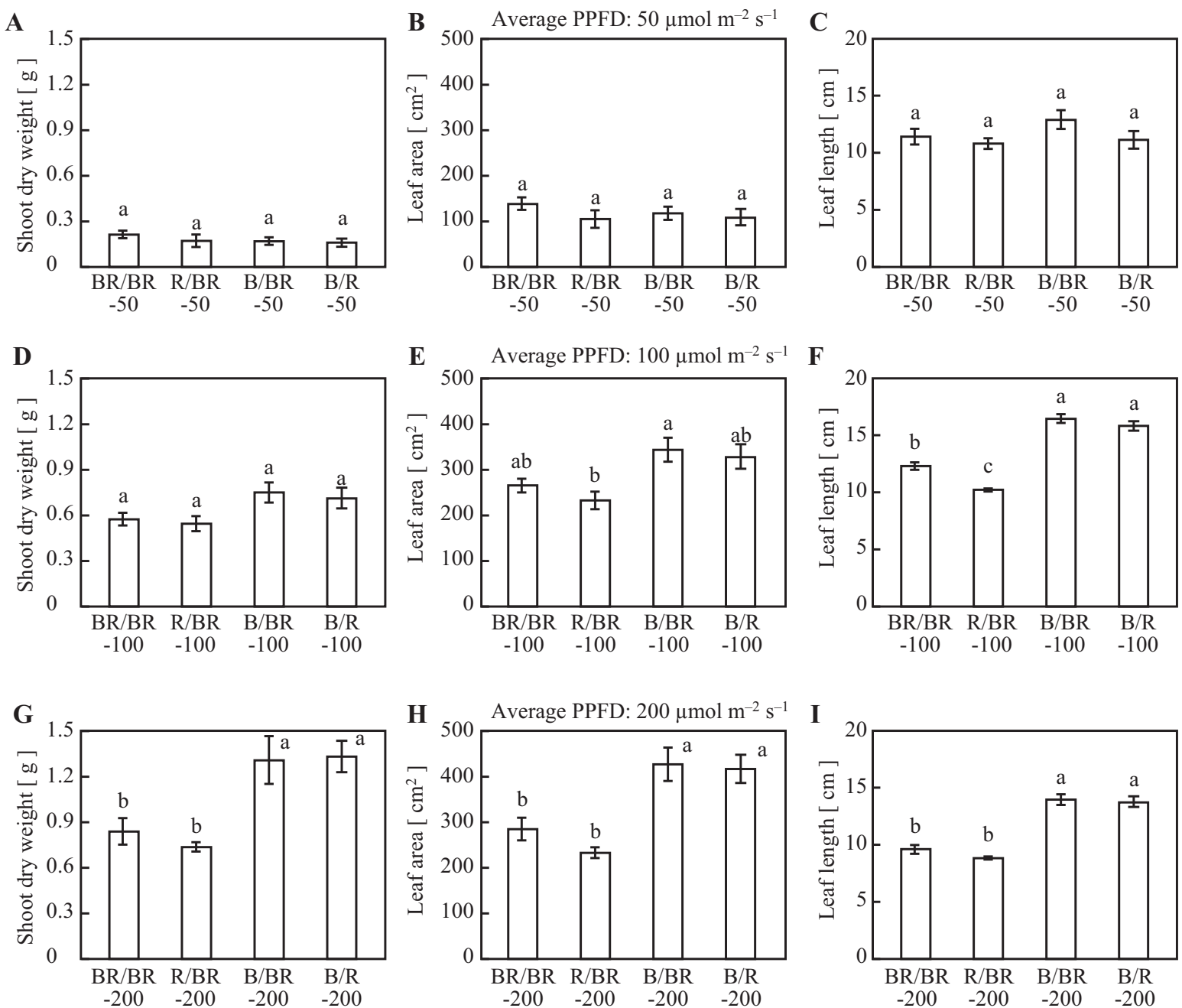

Fig. 4. (A, D, G) Shoot dry weight, $(\mathbf{B}, \mathbf{E}, \mathbf{H})$ leaf area, and $(\mathbf{C}, \mathbf{F}, \mathbf{I})$ leaf length of cos lettuce plants grown under each treatment with a daily average photosynthetic photon flux density (PPFD) of (A, B, C) 50, (D, E, F) 100 , or $(\mathbf{G}, \mathbf{H}, \mathbf{I}) 200 \mu \mathrm{mol} \cdot \mathrm{m}^{-2} \cdot \mathrm{s}^{-1}$. Error bars represent the standard error of the mean $(\mathrm{n}=8)$. Bars labeled with different lowercase letters in each panel differ significantly (Tukey-Kramer honestly significant difference test, $P=0.05)$.

and BR (which did not include B) showed that leaf area and leaf length tended to be smaller under R/BR, which also included $\mathrm{R}$ (Fig. 4). Thus, $\mathrm{R}$ tended to suppress increase in leaf area and leaf length.

\section{Discussion}

Effects of blue light monochromatic irradiation. Cos lettuce plants produced elongated leaves under irradiation with $B$ regardless of $\mathrm{PPFD}_{\text {ave. }}$ Leaf length was significantly greater with RSPFD change patterns of $\mathrm{BR} / \mathrm{B}$ and $B / R$ when the $P P F D_{\text {ave }}$ was 100 or $200 \mu \mathrm{mol} \cdot \mathrm{m}^{-2} \cdot \mathrm{s}^{-1}$. The mechanism of this elongation may be associated with the action of phytochrome B. Phytochrome is a photoreceptor that reversibly changes between an activated $\left(\mathrm{P}_{\mathrm{fr}}\right)$ and inactivated $\left(\mathrm{P}_{\mathrm{r}}\right)$ form (Borthwick et al., 1952; Butler et al., 1959) and induces the shade-avoidance response. Generally, stems are more elongated when the percentage of $\mathrm{P}_{\mathrm{fr}}$ is low (Franklin and Quail, 2010). The $\mathrm{P}_{\text {fr }}$ percentage can be

Table 2. Results of analysis of variance ( $P$ values) with average photosynthetic photon flux density $\left(\mathrm{PPFD}_{\mathrm{ave}}\right)$, and presence or absence of blue- (B) and red-light monochromatic irradiation (R) as the main factors for shoot dry weight, leaf area, and leaf length.

\begin{tabular}{lccc}
\hline & \multicolumn{3}{c}{$P$ value } \\
\cline { 2 - 4 } Source of variation & Shoot dry weight & Leaf area & Leaf length \\
\hline PPFD $_{\text {ave }}$ & $<0.001^{* *}$ & $<0.001^{* *}$ & 0.877 \\
$\mathrm{~B}$ presence & $<0.001^{* *}$ & $<0.001^{* *}$ & $<0.001^{* *}$ \\
$\mathrm{R}$ presence & 0.266 & $0.026^{*}$ & $0.002^{*}$ \\
$\mathrm{PPFD}_{\text {ave }} \times \mathrm{B}$ presence & $<0.001^{* *}$ & $<0.001^{* *}$ & $<0.001^{* *}$ \\
$\mathrm{PPFD}_{\text {ave }} \times \mathrm{R}$ presence & 0.847 & 0.725 & 0.360 \\
$\mathrm{~B}$ presence $\times \mathrm{R}$ presence & 0.393 & 0.207 & 0.696 \\
$\mathrm{PPFD}_{\text {ave }} \times \mathrm{B}$ presence $\times \mathrm{R}$ presence & 0.518 & 0.745 & 0.274 \\
\hline
\end{tabular}

estimated as the phytochrome photostationary state (PSS) with the RSPFD of irradiated light (Sager et al., 1988). The calculated PSS under $\mathrm{BR}$ was as high as that under R, whereas the PSS under B was significantly lower (Table 3). Thus, the reason for the leaf elongation observed under the treatments that included $\mathrm{B}$ can be considered to be the low PSS under B. Hernández and Kubota (2016)

Table 3. Phytochrome photostationary state

(PSS) under several photosynthetic photon flux density (PPFD) ratios of blue and red LED light in the present study.

PPFD ratio of $\mathrm{B} / \mathrm{R}$ light

\begin{tabular}{lll}
\hline $1 / 0$ & B & 0.55 \\
$2 / 1$ & BR (in R/BR patterns) & 0.88 \\
$1 / 1$ & BR (in BR/BR patterns) & 0.89 \\
$1 / 2$ & BR (in B/BR patterns) & 0.90 \\
$0 / 1$ & R & 0.91 \\
\hline
\end{tabular}

$\mathrm{B}=$ monochromatic blue-light irradiation; $\mathrm{BR}=$ simultaneous blue- and red-light irradiation; $\mathrm{R}=$ monochromatic red-light irradiation. The PSS values were calculated from the spectral photon flux densities (see Fig. 2) and photochemical cross-section data of Sager et al. (1988). 
previously reported that $\mathrm{B}$ promotes elongation in cucumber, probably because of low PSS, and the results of the present study show a similar phenomenon.

The shoot dry weights in B/BR-200 and B/R-200, which included $B$, were significantly higher than those under BR/BR-200 and R/BR-200. This growth promotion may have been caused by the increased amount of light received per plant as a result of leaf elongation because of $\mathrm{B}$.

Interactions between the effects of $B$ and $P P F D_{\text {ave }}$. There were interactions between the effects of $\mathrm{B}$ presence and PPFD $_{\text {ave }}$ for shoot dry weight, leaf area, and leaf length (Table 1). Irradiation with B increased shoot dry weight, leaf area, and leaf length only at higher $\mathrm{PPFD}_{\text {ave }}$ values. These interactions are likely to be caused by morphology. The specific leaf area (leaf area per leaf dry weight) of lettuce decreases at higher PPFDs (Kitaya et al., 1998), and leaves become thicker and more compact. Therefore, leaf elongation increases the amount of light received and the growth-promotive effects of B should be obvious at higher PPFD $_{\text {ave values. However, }}$ whereas the low PPFD ave of $50 \mu \mathrm{mol} \cdot \mathrm{m}^{-2} \cdot \mathrm{s}^{-1}$ contributed to leaf elongation, the combination of low PPFD $_{\text {ave }}$ and $\mathrm{B}$ resulted in excessive leaf elongation and caused the plants to fall over (Fig. 3C and D). The leaves of lodged plants cannot intercept light efficiently. Thus, excessive elongation did not promote growth (Fig. 4A) and, consequently, did not promote increase in leaf area and leaf length.

Effects of red-light monochromatic irradiation and duration of blue-light irradiation. According to the results of ANOVA, R presence affected leaf area and leaf length (Table 2) and tended to reduce these leaf parameters (Fig. 4). However, from the viewpoint of photoreceptors, it is natural to assume these results are associated with the effects of the duration of blue-light irradiation rather than to assume $\mathrm{R}$ itself affects plant morphology. In the present experiment, the treatments that included $\mathrm{R}(\mathrm{BR} / \mathrm{R}$ and $\mathrm{B} / \mathrm{R})$ had a short period $(12 \mathrm{~h}$ ) of blue-light irradiation (Table 1, Fig. 1). Blue light is known to promote flat leaf expansion via the action of blue light photoreceptors (Inoue et al., 2008). Therefore, the two RSPFD change patterns that had a long period $(24 \mathrm{~h})$ of blue-light irradiation (BR/BR and $\mathrm{BR} / \mathrm{B})$, that is, the treatments without $\mathrm{R}$, may have caused flattening and expansion of the leaves because of the reaction via blue light receptors.

Blue-light irradiation has also been reported to suppress stem elongation and leaf expansion (Eskins, 1992; Huché-Thelier et al., 2016), but these effects were not clearly observed in the present study. In this study, the DLI of blue light was the same among treatments in each PPFD level. One hypothesis is that the effects of blue light receptors may be affected not by the duration of blue light irradiation but by the daily blue light PPFD integral. Alternatively, the effect of blue light receptors might be saturated when the irradiation time exceeds $12 \mathrm{~h}$.
Irradiation pattern to promote growth. Irradiation with 12-h B caused leaf elongation and promoted growth of cos lettuce plants at higher PPFD $_{\text {ave }}$ levels. On the basis of this result, we may, for instance, be able to promote plant growth by eliminating red light in conventional simultaneous BR for certain periods. However, it is noteworthy that leaf elongation stimulated by B can have both a positive effect (increase in the amount of light received) and a negative effect (spindly growth) depending on other conditions, such as PPFD. Compared with the RSPFD change pattern in this study indicated that PPFD of $100-200 \mu \mathrm{mol} \cdot \mathrm{m}^{-2} \cdot \mathrm{s}^{-1}$ or higher was sufficiently high for B to contribute to growth promotion. A future task is to clarify the promotion of growth with B if the RSPFD change pattern is different.

In addition, leaf expansion only increases the amount of light received by plants when the leaves do not overlap. In the present study, the cos lettuce plants were harvested at an early stage of growth. Because the leaves did not shade each other at this time point, the plants received the full benefit of the increased amount of light received with the increased leaf area. When plant density is high and plants cast shade on each other, B may not increase the amount of light received per plant and may not promote growth as much as observed in the present study. Furthermore, the positions of the cultivation surface and the light source were fixed in the present study. The closer a surface is to the light source, the higher the PPFD. Larger seedlings thus generally receive more light, which may have increased the growth difference between larger and smaller seedlings. Thus, under other conditions, B may not promote growth as much as observed in the present study.

Far-red light has a greater plant elongation-promoting effect than blue light and may increase the leaf area and promote growth as observed in the present study. However, far red light is not effectively used for photosynthesis. Blue light is necessary for plant growth to cause blue light reactions, such as leaf flattening, and is used for photosynthesis with high efficiency. If phytochrome-dependent plant morphology can be controlled using B, it might be a useful plant growth technique compared with using far red light.

Cos lettuce is a variety with flat leaves and leaf elongation tends to increase the amount of light received. However, when leaf elongation of frillice lettuce was promoted, only the petiole was longer and the amount of light received did not increase notably (data not shown). Ohtake et al. (2018) showed that leaf lettuce growth was promoted in the $\mathrm{B} / \mathrm{R}$-corresponding treatment compared with the BR/BR-corresponding treatment. The authors suggested that a high photosynthetic rate per leaf area is a factor for promotion of growth. Leaf elongation by $\mathrm{B}$ is one factor in growth promotion, but there may be an additional mechanism for growth promotion under a light irradiation pattern with SPFD changes over time.

\section{Conclusions}

Cos lettuce leaves were elongated under RSPFD change patterns that included B, probably because of a phytochrome reaction. The increase in the amount of light received caused by leaf elongation in response to B should promote the growth of leafy crops when the PPFD exceeds a certain threshold. We must verify whether $B$ is effective in practical cultivation facilities with artificial lighting. Studies using other wavebands or other plant species are required to identify an effective artificial lighting method to control plant growth and morphology.

\section{Literature Cited}

Borthwick, H.A., S.B. Hendricks, M.W. Parker, E.H. Toole, and V.K. Toole. 1952. A reversible photoreaction controlling seed germination. Proc. Natl. Acad. Sci. USA 38(8):662-666, doi: $10.1073 /$ pnas.38.8.662.

Butler, W.L., K.H. Norris, H.W. Siegelman, and S.B. Hendricks. 1959. Detection, assay, and preliminary purification of the pigment controlling photoresponsive development of plants. Proc. Natl. Acad. Sci. USA 45(12):1703-1708, doi: 10.1073/pnas.45.12.1703.

Chen, X.L., Q.C. Yang, W.P. Song, L.C. Wang, W.Z. Guo, and X.Z. Xue. 2017. Growth and nutritional properties of lettuce affected by different alternating intervals of red and blue LED irradiation. Scientia Hort. 223:44-52.

Eskins, K. 1992. Light-quality effects on Arabidopsis development. Red, blue and far-red regulation of flowering and morphology. Physiol. Plant. 86(3):439-444, doi: 10.1111/j.13993054.1992.tb01341.x.

Fan, X. X., Z. G. Xu, X. Y. Liu, C. M. Tang, L. W. Wang, and X. lin. Han. 2013. Effects of light intensity on the growth and leaf development of young tomato plants grown under a combination of red and blue light. Scientia Hort. 153:50-55, doi: 10.1016/j.scienta.2013.01.017.

Franklin, K.A. and P.H. Quail. 2010. Phytochrome functions in Arabidopsis development. J. Expt. Bot. 61(1):11-24, doi: 10.1093/jxb/erp304.

Hernández, R. and C. Kubota. 2016. Physiological responses of cucumber seedlings under different blue and red photon flux ratios using LEDs. Environ. Exp. Bot. 121:66-74, doi: 10.1016/j.envexpbot.2015.04.001.

Hogewoning, S.W., G. Trouwborst, H. Maljaars, H. Poorter, W. van Ieperen, and J. Harbinson. 2010. Blue light dose-responses of leaf photosynthesis, morphology, and chemical composition of $\mathrm{Cucu}$ mis sativus grown under different combinations of red and blue light. J. Expt. Bot. 61(11): 3107-3117, http://dx.doi.ort/10.1093/jxb/erq132.

Huché-Thélier, L., L. Crespel, J. Le Gourrierec, P. Morel, S. Sakr, and N. Leduc. 2016. Light signaling and plant responses to blue and UV radiations-perspectives for applications in horticulture. Environ. Exp. Bot. 121:22-38, doi: 10.1016/j.envexpbot.2015.06.009.

Inoue, S., T. Kinoshita, A. Takemiya, M. Doi, and K. Shimazaki. 2008. Leaf positioning of Arabidopsis in response to blue light. Mol. Plant 1(1):15-26, doi: $10.1093 / \mathrm{mp} / \mathrm{ssm} 001$.

Jishi, T., K. Kimura, R. Matsuda, and K. Fujiwara. 2016. Effects of temporally shifted irradiation of blue and red LED light on cos lettuce growth 
and morphology. Scientia Hort. 198:227-232, doi: 10.1016/j.scienta.2015.12.005.

Kitaya, Y., G. Niu, T. Kozai, and M. Ohashi. 1998. Photosynthetic photon flux, photoperiod, and $\mathrm{CO}_{2}$ concentration affect growth and morphology of lettuce plug transplants. HortScience 36(6):988-991.

Liu, X., G. Shirong, C. Taotao, X. Zhigang, and T. Tezuka. 2012. Regulation of the growth and photosynthesis of cherry tomato seedlings by different light irradiations of light emitting diodes
(LED). Afr. J. Biotechnol. 11(22):6169-6177, doi: 10.5897/AJB11.1191.

Ohtake, N., M. Ishikura, and H. Suzuki. 2018. Continuous irradiation with alternating red and blue light enhances plant growth while keeping nutritional quality in lettuce. HortScience 53(12): 1804-1809, doi: 10.21273/HORTSCI13469-18.

Sager, J.C., W.O. Smith, J.L. Edwards, and K.L. Cyr. 1988. Photosynthetic efficiency and phytochrome photoequilibria determination using spectral data. Trans. ASAE 31:1882-1889.
ShimokawaA.Y. TonookaM. MatsumotoH. AraH. SuzukiN. Yamauchi, and M. Shigyo. 2014. Effect of alternating red and blue light irradiation generated by light emitting diodes on the growth of leaf lettuce. bioR $\chi$ iv. doi: 10.1101/ 003103.

Yorio, N.C., G.D. Goins, H.R. Kagie, R.M. Wheeler, and J.C. Sager. 2001. Improving spinach, radish, and lettuce growth under red light-emitting diodes (LEDs) with blue light supplementation. HortScience 36(2):380-383. 